\title{
The Trend Analysis of Life Insurance Premium Income Time Series Based on SARIMA Model in Underdeveloped Areas
}

\author{
-A Case Study of Guizhou Province
}

\author{
Xin $\mathrm{He}$ \\ School of Finance \\ Guizhou University of Finance and Economics \\ Guiyang, China \\ 121190731@qq.com
}

\author{
Hongmei Zhang* \\ School of Finance \\ Guizhou University of Finance and Economics \\ Guiyang, China \\ zhm1035@qq.com
}

\begin{abstract}
Based on the study of the development of life insurance in Guizhou Province in the underdeveloped areas, this paper analyzes the time series of premium income in Guizhou Province to study the development of life insurance in this area, and the paper mainly focuses on the monthly data of life insurance income from January 2009 to May 2017 in Guizhou province. By establishing the SARIMA model and interpreting the model, it is found that the premium income of life insurance has obvious seasonal characteristics, and that the premium income of life insurance premiums will be affected by the period, and the relevant suggestions are put forward.
\end{abstract}

Keywords-SARIMA model; life insurance premium income; Guizhou province; stability

\section{INTRODUCTION}

Life insurance is an important part of China's insurance market, with the improvement of China's economic level and social development, more and more people realize the importance of personal insurance. As far as the whole country is concerned, China's insurance industry, especially the development of life insurance, has great potential, but compared with the western developed countries; both the insurance depth and the insurance density have a big gap with the western countries. For China's underdeveloped western provinces, the level of insurance development and the eastern and central regions have a large gap, the overall performance of the East strong West weak, and the regional differences are growing, so it is necessary to study the development of life insurance in economically underdeveloped areas.

\section{LITERATURE REVIEW}

The research on life insurance demand in foreign countries started earlier. Yaari (1965) think that the uncertainty of life is introduced for the first time in the optimal analysis of consumer decision-making, and the traditional deterministic life-cycle model is modified creatively. Zhu (2007), Pliska and Ye (2007) think that the Family purchase life insurance and other family financial investment behaviors are included in the decision model, and the optimal combination of investment and consumption in the uncertain life is deduced, and their research

This work was supported by Guizhou University of Finance and Economics Insurance Workstation Project. results are the latest achievement of the theory of life insurance demand. On the basis of the above theoretical research, many scholars have carried out empirical research on specific countries based on macroscopic data of country and region, and compared with many countries.

Compared with foreign countries, the research on life insurance demand of Chinese scholars starts late and results less. Chu Jun Hong(1998) considers that the life insurance demand of China should be used to measure life insurance premium income, and the factors that affect the demand of life insurance are direct and indirect, and the change of life insurance price and the income level of residents are the direct factors that affect the life insurance demand, the state's fiscal and financial policy, the construction of social security system, the income distribution policy and the rate of inflation., interest rate and humane social environment are the indirect factors that affect the demand of life insurance, and the effect of inflation on life insurance demand is divided into price effect, income effect and substitution effect. Xiaowen and Shevenwu (2000) from the macroscopic data of 1980-1998 in China, it is found that the GDP has a significant impact on premium income, and the national rate reduction policy and the increases of market openness have a significant positive effect on life insurance demand. Kang Jianjun and Wang (2002) based on the personal insurance data of 1985-1997, through the time series model study, we find that the life insurance demand of our country is positively correlated with the income level of the residents and is not affected by the change of the state interest rate. Chen Zhichu and Liu Xiaojing (2004) from the macroscopic data of 1990-2001 years in our country, it is found that the demand of life insurance is positively correlated with the personal disposable income and social security of residents, and it is negatively correlated with Engel's coefficient and interest rate, and the saving has both income effect and substitution effect on life insurance demand. Shu Gaoyong and Shi Ying (2007) from 1982-2005 years ' life insurance data in China, it is found that the first demand is positively correlated with the level of income per capita and the level of urbanization, which is negatively correlated with the population mortality, and has no significant relationship with education level, inflation rate, nominal interest rate and social 
system. The empirical research on domestic life insurance needs is concentrated in developed cities or regions such as Beijing and Shanghai, and there are few literatures on the life insurance market in the underdeveloped areas.

\section{DATA SOURCE AND MODEL INTRODUCTION}

\section{A. Date sources}

This paper collects the data of life insurance premiums from January 2009 to May 2017 in Guizhou Province, a total of 101 sets of data, the data from the official website of China Bureau of Statistics. Using computer software to analyze the monthly data of life insurance premiums in Guizhou province from January 2009 to May 2017, we construct effective ARIMA (p, D, Q) (P, D, Q) models.

\section{B. Model Introduction}

In some time series, there are obvious periodic changes. This cycle is caused by seasonal variations (including Quarterly, Monthly, Zhou Du, etc.) or other factors such as seasonal sequences. In the economic field and economic research process, seasonal time series is more common, such as quarterly time series, monthly time series, and weekly time series and so on.

The autoregressive moving average model, which was first proposed in 1970 by American statisticians G. E. P. Box and G. Jenkins, is widely used in all kinds of time series data analysis, and is a short-term forecasting method with high prediction precision. It is necessary to use computer software to build up the complex model calculation.

The essence of ARIMA model is the combination of difference operation and ARMA model. This relationship is of great significance. It is indicated that any non-stationary sequence can be stabilized by the difference of proper order number, and the ARMA model can be combined with the differential sequence. The analysis method of ARMA model is very mature, which means that the analysis of the differential stationary sequence will be very simple and reliable, and the accuracy of the predicted results will be improved.

\section{Modeling and prediction of four or one-element time series}

In the process of modeling a unary time series, it is first necessary to determine whether the sequence is stable and seasonal. There are two main methods of judging time series: first, the general judgment of the trend chart of time series. Second, judging by the autocorrelation diagram of time series. The first step to solve the problem of seasonal and Nonstationary time series is to stabilize the sequence variance by means of logarithmic transformation. The second step is to eliminate the long-term trend of the sequence by differential elimination, and then the seasonal difference is used to eliminate the time series.

The following picture shows the monthly time data of life insurance premium income (BF), it is obvious that it has a strong periodicity with the change of time, although the trend of overall change is not very obvious,. In addition, it can be seen that the life insurance premium income (BF) in the year of January and then will gradually come down, although the middle of the month will be high but obviously weak, will not reach the January income level, which is strongly related to the business model of Chinese insurance companies, The marketing feature of the Chinese insurance company is that it will finish the whole year ahead of January.

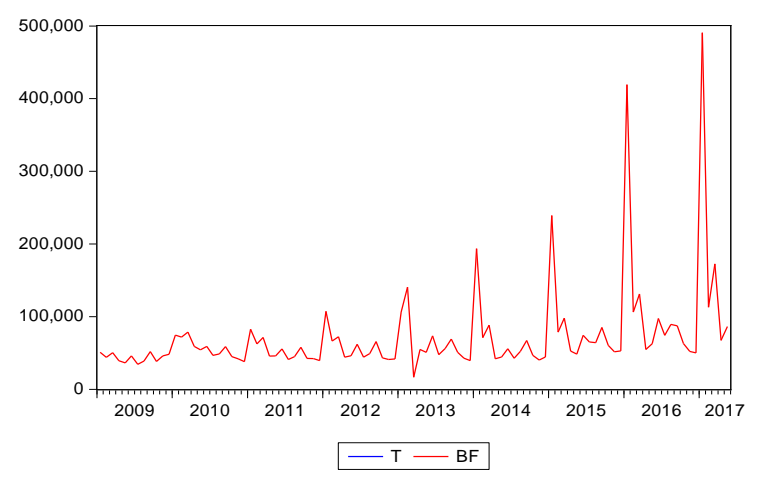

Fig. 1. Life Insurance Premium Income(BF) sequence diagram

Life Insurance Premium Income (BF) from 2009 to 2017, the fluctuation amplitude is relatively large, that is, the sequence of the mean and variance of the change is relatively large, which belongs to Nonstationary time series. There is a serious increment of variance in the time series, so we need to $\log$ the life insurance premium income (BF) time series to obtain the logarithm sequence (LOGBF) of the insurance premium income, such as graph, logarithmic processing can not only reduce the volatility of the sequence, but also can eliminate the variance. At the same time, the Non-stationary time series is transformed into a stationary time series by differential processing of the sequence.

\section{LOGBF}

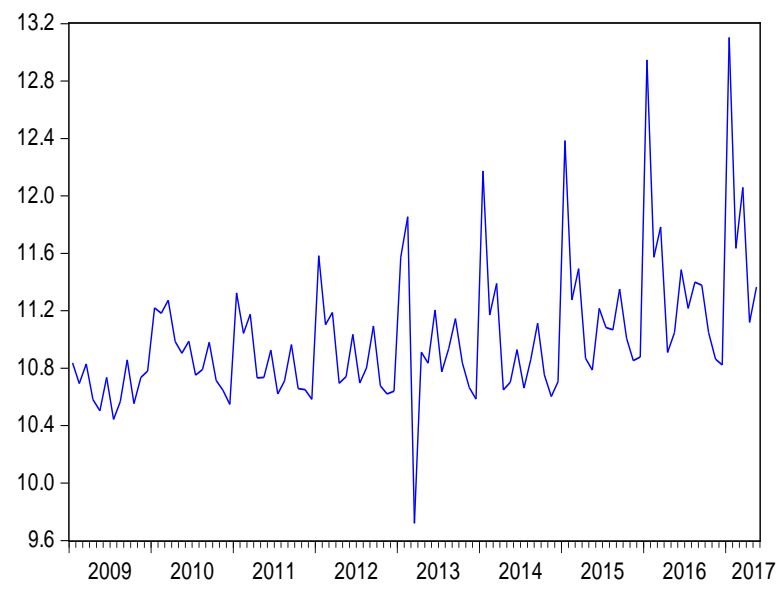

Fig. 2. A differential post-life insurance premium income(LOGBF) sequence diagram 
DLOGBF

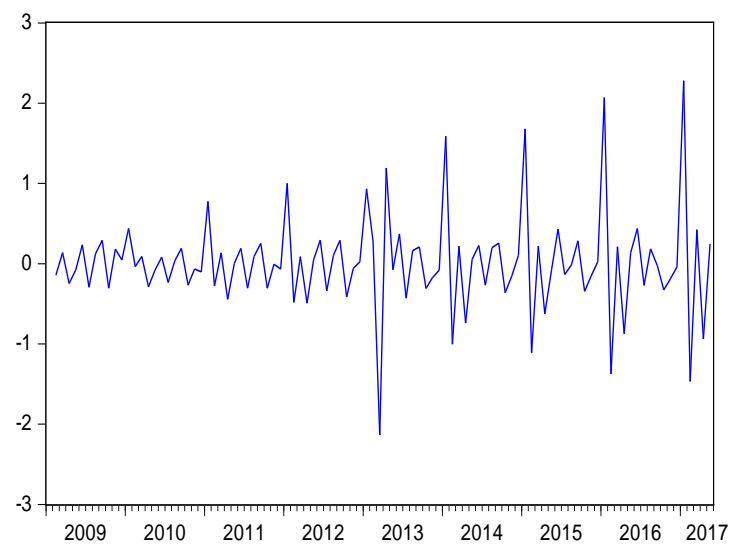

Fig. 3. Difference Post life Insurance premium income(DLOGBF) sequence diagram

However, it is obvious that the logarithm sequence (LOGBF) and differential sequence (LOGBF) of life insurance premium income can be observed periodically, which should be caused by seasonal factors, so it is necessary to adjust the differential sequence (LOGBF) seasonally, after a seasonal differential treatment, the LOGBF sequence is obtained.

\section{DDLOGBF12}

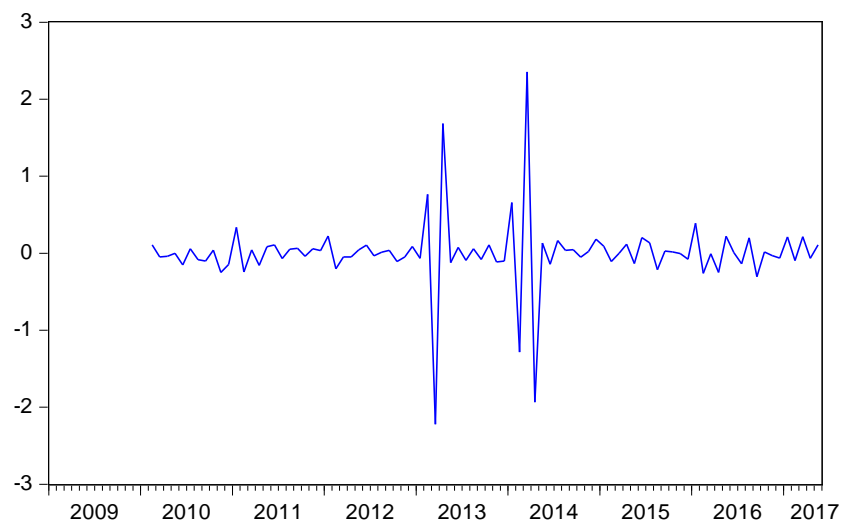

Fig. 4. Seasonally Adjusted Insurance premium income(DDLOGBF12) sequence diagram

The equations are an exception to the prescribed specifications of this template. You will need to determine whether or not your equation should be typed using either the Times New Roman or the Symbol font (please no other font). To create multileveled equations, it may be necessary to treat the equation as a graphic and insert it into the text after your paper is styled.

Through the above-mentioned series of tests, it is known that the original sequence (BF) is stable and has no tendency after the logarithm processing, the first difference, the one-time adjustment difference, and then the $d=d=1$ is recognized as the LOGBF. So the next step is to identify the model by checking the autocorrelation function and the partial correlation function of the sequence. So the final model should be defined as: the seasonal ARIMA $(0,1,1)(0,1,1)$ or Sarima $(0,1,1)(0,1$ and $1)$, the model is also known as the route model.

To return the data, estimated results of the model are as follows:

$$
\left(\Delta \Delta_{12} L O G B F-0.002\right)=(1-0.9669 L)\left(1-0.5587 L^{12}\right) \mu_{t}
$$

According to the output, the estimated value of the moving average coefficient is all significant (the value of $\mathrm{T}$ statistic is greater than 2), 13 characteristic roots are less than 1 , so their characteristic roots are outside the unit circle, so the above estimation model can be identified as the final model.

\section{CONCLUSIONS AND POLICY RECOMMENDATIONS}

The seasonal characteristics of life insurance premium income are related to the marketing means and sales mode of Chinese insurance companies. At home, every insurance company attaches great importance to the "big start", the insurance industry has a "start up, year-round red", which shows that insurers will devote huge manpower and material resources to the January and the first quarter of the marketing work, so that the January and the first quarter of life insurance premiums significantly higher than the other months. Subsequent premiums in other months will be affected by the January and the first quarter, making premiums lower than the annual January and first-quarter premium income, and the short-term performance and premium income will not exceed January's performance. Therefore, in Guizhou Province, even nationwide, life insurance premiums will show obvious seasonal characteristics.

Current premium income related to previous performance. Because the natures of insurance products introduced by insurance companies are mostly similar, most of them are paid by instalments, so the premium income has a strong lag. From the above estimation model, the life insurance premium income has a strong correlation with each period is positively related to the present, this is because the insurance company in the market for a certain period of time on the product sales, the next period of premium income will be affected by the current sale of products. And there is a positive correlation, which is due to the time period factor, the first 12 months are in the life insurance policy validity period, and the current premium income has a positive correlation. It is a negative correlation, because by the end of the 13th month, or one month after the end of the one-year policy, a full policy year has ended, and the insurance product will face expiration or some insurance buyers will be insured.

The premium income increases with the level of economic development, that is to say, there is a positive correlation between the degree of insurance developed in one area and the level of economic development. The better the level of economic development in a region, the higher the disposable income of residents, the higher the residents ' insurance demand. Therefore, in view of the actual situation in Guizhou Province, the main task is to develop the economy, enhance the disposable income of the residents, seize all the platforms that can develop the economy, for example, based on the development of large data, ecological, large-poverty policy call 
to improve the living standards of the residents, to stimulate the potential.

The insurance company should design and sell the insurance products suitable for the characteristics of the residents in Guizhou province according to the different economic development degree, the customer's economic ability and characteristics, and excavate the recessive demand of the insurance market in Guizhou province. Life insurance companies should actively develop some new life insurance products, so that the predetermined rate of interest can be adjusted with the change of the bank's deposit rate in one year, so as to avoid some customers to choose to retreat when the interest rate is raised, and to some extent to avoid the risk of loss of interest of the insurer when the bank Rate is lowered. At the same time, in view of the children's education, health, accidental injury and the insurance needs of the elderly, the insurance companies in Guizhou should increase the development of the corresponding insurance products to meet the diverse needs of the consumers under the one-child policy and the age-old background of population aging. actively develop and design insurance products for all age groups, fully develop the insurance demand of Guizhou province and enhance the ability of commercial security, to make up for the insufficiency of social security.

\section{ACKNOWLEDGMENT}

This work was supported by Guizhou University of Finance and Economics Insurance Workstation Project--The analysis of life insurance demand in underdeveloped areas.

\section{REFERENCES}

[1] Sun Jingyun,Tian Lina.Time series forecast of premium income of insurance companies in China [J]. Journal of Gansu Sciences. 2011(12):143-145.

[2] Su Gaoyong, Shi Yong. Empirical analysis on the demand of life insurance industry in China [J]. Insurance Studies. 2007, (6):36-39.

[3] Huang Shushan,Li Kaibin.On the potential demand of commercial insurance market in China [J]. Insurance Studies.1999,4

[4] Wang Hui.Demand analysis of Chinese life insurance market[J]. Science-technology and Management, 2003,5

[5] Sun Qixiang,Hui Ben.Analysis of supply and demand scale of insurance industry development in China [J]. Economic Research Journal, 1997(3):55-61

[6] Liang Laicun.An empirical analysis of life insurance demand in China [J]. .The Journal of Quantitative \& Technical Economics, 2007(8):80-89.

[7] Qian Zhen.An empirical analysis of the influence factors of non-life insurance in China [J]. Statistical Education, 2006(8):27- 29. 